\title{
ENURESIS OF ALLERGIC ORIGIN
}

B Y

\author{
GEORGE W. BRAY, M.B., Ch.M.
}

(From the Asthma Clinic, The Hospital for Sick Children, Gieat

Ormond Street, London.)

Persistent enures.s is a common complaint, difficult to eradicate and obnoxious to all concerned, whether patient, parent, or physician. It is not my desire, in this preliminary communication, to recapitulate the multitudinous ætiological factors nor discuss the numerous recognized therapeutic aids in this condition, but rather to expand an observation which I made in an article on the asthmatic child which appeared in this journal last vear ${ }^{1}$. In this I stated that, in my experience, a few cases of persistent enuresis in children were allergic in origin. The cases to which I referred may be classed into three categories :-First, cases in which enuresis occurs along with such allerric manifestations as asthma, hay-ferer, eczema, urticaria and migraine : secondly, cases in which enuresis is present along with conditions that hare proved allergic in origin; thirdly, cases in which enuresis occurs as the sole manifestation of allergy.

Parents of young allergic children are loath to admit that the child wets himself as they regard it as an infantile weakness that will soon disappear at the age of seven or puberty. They are always more concerned with the asthma or other allergic complaint that has commenced recently and which, in their view, is liable to persist throughout life. It is only in the case of older children that the statement is rolunteered, for they have been distracted to find that the habit did not cease with the second dentition. In a thousand allergic children I have found that 5 per cent. over the age of seven vears suffer from some degree of enuresis.

If we compare the nerre supply of the bladder with that of the lungs the reason for the association between enuresis and such an allergic condition as asthma becomes obvious. For just as constrictor fibres are supplied to the smooth muscle in the walls of the bronchi through the cranial division of the parasympathetic system, motor fibres are supplied to the detrusor muscle of the bladder and inhibitory fibres to the internal resical sphincter through the sacral division of the same system. On the contrary, the bronchi are dilated through sympathetic fibres inhibiting their smooth muscle, and the internal sphincter of the bladder and the trigonal region are contracted and the detrusor muscle inhibited through a similar innervation. Obviously stimulation of the parasympathetic system may lead to bronchospasm, or to the discharge of urine, or both, according to the location or intensity of the stimulus, whilst any endeavour to stimulate the sympathetic to counteract the asthmatic tendency may lead, in addition, to the cessation of a bed-wetting habit. 
Clinical eridence supports this suggestion, for one of the distressing effects of ephedrine in some patients is to lead to an inability to micturate due to a spasmodic constriction of the resical sphincter.

The analogy between enuresis and allergic conditions in general does not cease with the similarity in innervation of the affected organs. Both conditions tend to occur in bouts with intervals of comparative freedom, both tend to be worse at night, both tend to be accentuated by fatigue or worry probably due to sympathetic exhaustion, and both commonly clear up on admission to hospital.

First, the cases in which enuresis is associated with other evidences of allergy are frequent. The sensitizing proteins may be foods, animal emanations or physical agents either singly or in combination. In some cases the same protein causes both the enuresis and other allergic reaction, whilst in other cases different proteins are concerned.

W.S., a bor aged five rears, had always wet the bed. For three months he had had asthmatic attacks each week-end, which were alwars preceded by intense stomach-ache and accompanied by more frequent lapses. In spite of fluid restrictions, the administration of belladonna, and waking at specified intervals, the habit continued unabated. Skin tests revealed a hyper-sensitivity to wheat, and forced feeding of wheaten foods over sereral days always brought on the stomach-ache and enuresis. Since the rigid restriction of wheaten foods eighteen months ago neither the asthma nor the enuresis have reappeared.

B.C.. a bor of eleven rears, had suffered from enuresis always and from asthma every three weeks for the past four vears. His maternal grandmother suffered from asthma. He gare huge skin reactions to feathers and rabbit hair which comprised his bedding, and their remoral led to a cessation of both complaints.

P.L., a bor aged three rears, suffered from facial eczema. asthma, and enuresis. There was a strong family history of allergy on the mother's side. The boy gave positive skin reactions to feathers, horsehair, egg. pork, potato and rice, the removal of which relieved all symptoms.

Secondly, in some cases enuresis accompanies other conditions that have proved allergic in origin.

C.C., a girl of three and a half rears, had wet the bed since birth. and for the past eighteen months had had several severe crops of lichen urticatus. The child's maternal grandmother suffered from asthma. Positive skin reactions were obtained to pork, and by eliminating all pork, bacon and lard from the diet four months ago the child has not wet the bed once nor hare any more spots appeared.

Besides lichen urticatus, enuresis frequently appears during recurrent colds and persists during the illness. Many of these recurrent bronchitic attacks are allergic in origin and due to a hyper-sensitiveness to feather or horsehair bedding, or in spring and summer colds to pollen hyper-sensitiveness which generally passes unrecognized.

These observations in definite cases of allergy suggested the inrestigation of some cases in which persistent enuresis was the sole complaint. Many older children who had suffered for several years from this habit and who had been treated in the outpatient department of the hospital for many years with dietary and fluid restrictions and large doses of belladonna without avail, and in whom no urinary abnormalities could be detected, were investigated, and three cases out of fifteen responded to the elimination of substances giving positive skin reactions. 
R.P., a girl of ten and a half years. had suffered from diurnal and nocturnal incontinence since birth without intermission. All the boys in the father's family had suffered from enuresis. She had been under constant medical care for some years without any response to the usual therapy. She was found hyper-sensitive to oatmeal. potato, rice and feathers, and since the elimination of these factors a year ago there has not been a wet bed.

The types of case quoted could be amplified', but the few chosen serre to illustrate the point that I have endearoured to stress, namely, that some cases of persistent enuresis are allergic in origin. In cases of this complaint which fail to respond to the routine therapy of waking, fluid restrictions and belladonna the protein skin tests may indicate a causal factor, and its elimination, possibly combined with judicious doses of ephedrine, will probably lead to a prompt cessation of the habit.

\section{REFERENCES.}

1. Bray, G., Arch. Dis. Childh., London, 1930, V, 237.

2. Bray, G., Recent Adrances in Allergy, London, 1931. 